\title{
An Observational Study of the Association between Adenovirus 36 Antibody Status and Weight Loss among Youth
}

\author{
Jillon S. Vander Wal ${ }^{a}$ Jean Huelsing ${ }^{b}$ Olga Dubuisson ${ }^{c}$ \\ Nikhil V. Dhurandhar ${ }^{c}$ \\ ${ }^{a}$ Department of Psychology, Saint Louis University, St. Louis, MO, b Living Well Foundation, \\ Imperial, MO, 'Pennington Biomedical Research Center, Louisiana State University System, \\ Baton Rouge, LA, USA
}

\section{Key Words}

Adenoviruses · Ad-36 · Lipids · Obesity · Pediatrics · Physical fitness · Weight loss

\begin{abstract}
Objective: Although the human adenovirus $36(\mathrm{Ad}-36)$ is associated with obesity and relative hypolipidemia, its role in pediatric weight loss treatment response is uncertain. Therefore, the primary study objective was to determine whether Ad-36 antibody (AB) status was associated with response to a pediatric weight loss program. The secondary objective was to assess the association between Ad-36 AB status and baseline lipid values. Methods: Participants included 73 youth aged $10-17$ years in a residential camp-based weight loss program. The study examined differences in baseline lipid values between $A d-36 A B+$ and $A B-$ youth as well as differences in response to treatment, including indices of body size and fitness. Results: At baseline, results showed that $A d-36 A B+$ youth evidenced significantly lower levels of total cholesterol and triglycerides than Ad-36 AB-youth (all $p<0.05$ ). After 4 weeks of treatment, the $A d-36 A B+$ youth showed a smaller reduction in $B M I$ percentile than the $A d-36 A B-$ youth $(p<0.05)$, a difference of about $0.48 \mathrm{~kg}$. Conclusion: Ad-36 AB status showed a weak association with treatment response, but was associated with a better lipid profile. Ad-36 AB status should be assessed in studies of pediatric obesity treatment and prevention.
\end{abstract}

Copyright (c) 2013 S. Karger GmbH, Freiburg

\section{Introduction}

In the USA, about 35\% of youth between the ages of 6 and 19 years are overweight or obese [1]. Pediatric overweight and obesity are associated with adverse health conditions [2, 3] that, if untreated, extend into adulthood with higher all-cause mortality rates [4] and 
Vander Wal et al.: An Observational Study of the Association between Adenovirus 36 Antibody Status and Weight Loss among Youth

decreased life expectancy [5]. Further, overweight and obesity are associated with peer victimization and stigma which may mediate the association between pediatric obesity and psychosocial outcomes [6].

The majority of research has focused on environmental contributions to obesity, including unfavorable changes in diet and physical activity [7]. At the same time, the prevalence of child obesity has more than tripled over the past three decades [1], and some youth are more susceptible to what has been termed an 'obesogenic environment' than others [8]. Changes in diet and physical activity alone may not be sufficient to account for this increase [7] nor explain individual differences. Collectively, these findings suggest that less studied putative causal mechanisms, such as viruses [9], merit attention.

A recently identified candidate that may play a role in the onset and maintenance of pediatric obesity is the human adenovirus 36 (Ad-36). Adenoviruses are naturally occurring viruses that typically result in upper respiratory infections or gastrointestinal distress. Ad-36 has been shown to increase adiposity when introduced into healthy animals, yet is associated with lower cholesterol and triglyceride concentrations [10-14]. Specifically, Ad-36 may induce obesity via inflammatory processes [13].

Research generally supports an association between the presence of Ad-36 antibodies (ABs) and obesity in humans [15]. Among adults, 5 studies, two in the USA [16], one in Italy [17], and two in Italian patients with non-alcoholic fatty liver disease demonstrate this association $[18,19]$.

However, 3 adult studies do not show an association between Ad36 AB status and obesity $[20,21]$. While a different response in various populations to Ad36 infection is possible, debate exists over the definition of obesity and use of highly physically fit subjects in a US study [20]. For a second study [21], conducted in Belgium and the Netherlands, the conduct of the assays for the determination of Ad-36 AB status has been debated [22, 23]. A study conducted in South Korea also found no association between Ad-36 infection and obesity, but did show an association between Ad-36 infection and overweight [24]. Of note, the Ad-36 prevalence rate among the overweight group (40\%) was markedly higher than has been previously reported.

In children, three studies show an association between Ad-36 ABs and obesity. Among children recruited from primary care clinics in the USA, $22 \%$ of obese children tested Ad-36 $\mathrm{AB}+$ compared with $7 \%$ of non-obese children [25]. Among predominantly overweight and obese children being seen in a general pediatric or pediatric obesity unit in South Korea, $30 \%$ tested Ad-36 AB+ [26]. Among South Korean children and adolescents, $28.5 \%$ of obese youth, compared with $13.6 \%$ of non-obese youth, tested Ad-36 AB+ [27]. Collectively, these studies support an association between a history of Ad-36 infection and obesity among youth.

Although Ad-36 induces a relative hypolipidemia in experimentally infected animals, the association between a history of Ad-36 infection and lipid profiles is uncertain among human adults. While a US study showed that $\mathrm{Ad}-36 \mathrm{AB}+$ participants had healthier lipid profiles than Ad-36 AB-participants [16], an Italian study showed that Ad-36 AB+ participants had higher triglycerides and lower high-density lipoprotein cholesterol (HDL) than Ad-36 AB- participants [17]. A Korean study found healthier HDL and triglyceride levels among Ad-36 AB+ adults compared with Ad-36 AB- adults, but higher total cholesterol among Ad-36 AB+ obese adults [24]. Finally, Ad-36 AB+ status, compared with Ad-36 AB- status, is associated with a lower occurrence of non-alcoholic fatty liver disease among obese persons [18].

Reports of an association of Ad-36 AB status with lipids among youth are similarly inconsistent. Among predominantly overweight and obese children examined in a general pediatric or pediatric obesity unit in South Korea, Ad-36 AB+ children had higher BMI indices, weight, and waist circumferences than Ad-36 AB- children [26]. Despite this, there were no differences in total cholesterol. In contrast, a different research group reported that among 
Vander Wal et al:: An Observational Study of the Association between Adenovirus 36 Antibody Status and Weight Loss among Youth

South Korean school children, Ad-36 AB+ children had higher BMIs, weight, and waist circumferences than Ad-36 AB- children [27]. However, the Ad-36 AB+ obese children showed higher triglyceride, total cholesterol, and low-density lipoprotein cholesterol (LDL) values than obese Ad-36 AB- children.

Given an association between $\mathrm{Ad}-36 \mathrm{AB}+$ status and obesity, one might hypothesize that Ad-36 AB+ status might impede weight loss. However, among adults with fatty liver disease, Ad-36 AB+ patients lost a greater amount of weight than Ad-36 AB-patients over the course of 1 year [19]. It should be noted that the intervention included smoking cessation (associated with weight gain) and the proportion of smokers among the Ad-36 AB+ and AB-groups is not reported. The association, if any, between Ad-36 AB status and weight loss among youth is not known.

Therefore, the first objective of the present study was to determine whether Ad-36 AB status was associated with reduction in measures of body size among youth between the ages of 10 and 17 years. The second objective was to assess the association between Ad-36 AB status and baseline lipid values given the disparity in results obtained among children compared with adults.

\section{Participants and Methods}

\section{Participants}

Participants included youth between the ages of 10 and 17 years enrolled at a residential summer weight loss camp. Exclusion criteria include fear of blood or needles, use of medication that causes weight loss or weight gain, genetic conditions associated with overweight or obesity, and illnesses that affect weight. Data were collected during the first 4-week camp session. Parents provided written informed consent; youth provided written informed assent. The study was approved by the Institutional Review Board of Saint Louis University.

\section{Measures}

Demographic characteristics included age, gender, and race. Height was measured to the nearest $1 / 8$ th inch according to a wall-mounted stadiometer. Weight was measured to the nearest 0.5 pound in light weight clothing, without shoes, on a digital scale at the beginning of the day following an overnight fast. BMI was calculated according to the equation (weight in $\mathrm{kg} /$ height in squared meters). Population-based age- and sex-specific BMI percentiles and z-scores were calculated using the EpiInfo program version 3.3.2 [28]. Physical fitness was assessed via a 1-mile run on a packed-gravel track and recorded in minutes and seconds.

Supplemental measures of body size (neck, waist, and hip circumference) and fitness (blood pressure, and sits-ups/min) were available for a subset of youth. Blood pressure was measured via a manual sphygmomanometer using an appropriate cuff size after youth had remained quietly seated in an air conditioned room for 8-10 $\mathrm{min}$.

\section{Detection of Lipids and Ad-36 ABs in Serum}

$\mathrm{AB}$ status and fasting lipids (cholesterol, HDL, LDL, triglycerides) were determined from a $5 \mathrm{ml}$ blood draw. Neutralizing antibodies to Ad-36 were determined by a constant virus, decreasing serum method as has been previously described [16].

\section{Procedures}

One month prior to starting camp, parents were sent a letter about the study, a copy of the study consent form, and an informational sheet on the virus. On the first day of camp, the principal investigator (PI) and a research assistant met with each family to review the consent and assent forms, address questions, and obtain informed consent. The next morning before breakfast, youth reported to camp headquarters for physiological measurements (i.e., height, weight, body size, and blood pressure). Following these measures, youth reported to the meeting hall for fasting blood draws. One-mile run/walk times and sit-ups/min were taken later that day. Blood samples were labeled with a random number and sent to Pennington Biomedical Research Center for analysis. Measures of body size and physical fitness were repeated during the last full day of camp. 
Vander Wal et al.: An Observational Study of the Association between Adenovirus 36 Antibody Status and Weight Loss among Youth

Intervention

A comprehensive description of the residential summer weight loss camp has been previously published [29]. The purpose of the camp is to provide a comprehensive, structured, youth-friendly weight management program that addresses diet, physical activity, and psychosocial functioning using the WIT ${ }^{\circledR}$ program developed by Camp Jump Start (see www.campjumpstart.com). A youth-friendly menu of 1,500 cal/day is provided (1,400-1,500 cal/day for girls; 1,500-1,600 cal/day for boys), including three 400- to 500-cal meals and two 100- to 150-cal snacks. The diet, classified as low-fat and high fiber, is nutritionally balanced and supplies adequate protein and micronutrients for youth. Food is served only in the dining hall under the direction of a registered dietitian.

Power

The study was powered according to previous findings regarding the prevalence of Ad-36 ABs as well as expected weight loss. Previous studies have shown an average Ad-36 AB+ prevalence rate of 22-30\% among overweight and obese children $[16,25]$. A previous study conducted at the same camp attained an enrollment of 76 campers and showed average reductions of $3.29 \pm 1.50 \mathrm{~kg} / \mathrm{m}^{2}$ in BMI, $0.23 \pm 0.13 \mathrm{in} \mathrm{z}$-BMI, and $3.80 \pm 1.89 \mathrm{~kg}$, the primary study outcomes [29]. Assuming the participation of 70 campers, a $25 \%$ prevalence rate, and that $\mathrm{Ad}-36 \mathrm{AB}+$ youth would lose $50 \%$ of the weight lost by Ad-36 AB-youth, the power to detect the primary outcomes would exceed 0.88 . If only 60 campers participated, with an $\mathrm{Ad}-36 \mathrm{AB}+$ prevalence of $20 \%$, power would range from 0.77 to 0.92 across primary outcomes.

Analyses

Descriptive statistics, including measures of central tendency and distribution, were used to describe youth at the group as well as sub-group level (Ad-36 AB+/-). Chi-square was used to test for differences in the proportion of girls and boys in the Ad-36 AB+ and Ad-36 AB- groups. Analyses of variance were used to compare Ad-36 AB+ and Ad-36 AB- youth at baseline on indices of body size, lipids, and fitness. Analyses of covariance were used to compare Ad-36 AB+ and Ad-36 AB-youth at baseline on indices of lipids and fitness while controlling for z-BMI. Given equivalent gender distributions in the Ad-36 AB+ and Ad-36 AB- groups, within-subjects t tests were used to examine the effectiveness of the intervention for the entire group as well as for the Ad-36 AB+ and Ad-36 AB- subgroups. Analyses of covariance were used to examine differences in weight loss outcomes, treating baseline values as covariates as has been recommended for analysis of change [30]. Multiple regression analyses were used to identify predictors of change in z-BMI. A two-tailed p value of 0.05 was adopted for all analyses.

\section{Results}

\section{Demographic Information}

Baseline demographic characteristics (defined as age and gender), lipids (defined as total cholesterol, HDL, LDL, and triglycerides), measures of body size (defined as height, weight, BMI, BMI percentile, z-BMI as well as neck, waist, and hip circumference), and physical fitness (blood pressure, run time, sit-ups/min) are presented in table 1 . The total sample was comprised of 73 youth, including 16 boys $(21.9 \%)$ and 57 girls $(78.1 \%)$, the majority of whom were Caucasian (84.9\%). 17 youth (23.3\%; 2 boys, 15 girls) tested Ad-36 AB+ and 56 youth (76.6\%; 14 boys, 42 girls) tested Ad-36 AB-. All but 3 youth were above the 95th BMI percentile for age and gender. The data are presented according to Ad-36 AB status in table 2. Lipids were unavailable for $2 \mathrm{Ad}-36 \mathrm{AB}-$ youth as one had an insufficient amount of blood drawn and the other ate breakfast prior to the blood draw. Demographics, measures of body size, and physical fitness could not be paired with Ad-36 AB status and lipid values for $1 \mathrm{Ad}-36 \mathrm{AB}+$ and $1 \mathrm{Ad}-36 \mathrm{AB}-$ youth due to the provision of nicknames to the investigators.

\section{Baseline Differences}

There were no significant differences in demographic characteristics at baseline between the Ad-36 AB+ and Ad-36 AB- groups. Specifically, the proportion of boys in the Ad-36 AB+ 
Table 1. Sample demographic, lipid, body size, and fitness characteristics $(n=73)$

\begin{tabular}{|c|c|c|}
\hline & Mean & SD \\
\hline \multicolumn{3}{|l|}{ Demographics } \\
\hline Age, years & 13.44 & 1.96 \\
\hline \multicolumn{3}{|l|}{ Lipids } \\
\hline Cholesterol, mg/dl ${ }^{\mathrm{a}}$ & 172.18 & 37.46 \\
\hline $\mathrm{HDL}, \mathrm{mg} / \mathrm{dl}^{\mathrm{a}}$ & 38.39 & 9.66 \\
\hline $\mathrm{LDL}, \mathrm{mg} / \mathrm{dl}^{\mathrm{b}}$ & 112.06 & 31.22 \\
\hline $\mathrm{TG}, \mathrm{mg} / \mathrm{dl}^{\mathrm{b}}$ & 108.68 & 53.54 \\
\hline \multicolumn{3}{|l|}{ Body size } \\
\hline Height, cm & 159.46 & 9.24 \\
\hline Weight, kg & 86.67 & 20.28 \\
\hline BMI, kg/m² & 33.77 & 5.84 \\
\hline BMI percentile & 98.08 & 2.07 \\
\hline z-BMI & 2.21 & 0.36 \\
\hline Neck circumference, $\mathrm{cm}$ & 36.84 & 3.44 \\
\hline Waist circumference, $\mathrm{cm}$ & 112.34 & 14.21 \\
\hline Hip circumference, $\mathrm{cm}$ & 110.98 & 12.13 \\
\hline \multicolumn{3}{|l|}{ Fitness } \\
\hline BP systolic, mm Hg & 123.67 & 17.08 \\
\hline BP diastolic, mm Hg & 72.05 & 9.44 \\
\hline Run time, min & 15.25 & 3.14 \\
\hline Sit-ups/min, $\mathrm{n}$ & 40.88 & 12.26 \\
\hline \multicolumn{3}{|c|}{$\begin{array}{l}\text { BP = Blood pressure } T G=\text { triglycerides. } \\
{ }^{a} n=72 \text { because one serum sample was of insufficient size. } \\
{ }^{b} n=71 \text { because the values of one child who ate breakfast were } \\
\text { moved. }\end{array}$} \\
\hline
\end{tabular}

and Ad-36 AB- groups did not significantly differ, $x^{2}(1)=1.34, p=$ ns. Further, there were no differences in age between the Ad-36 AB+ and Ad-36 AB-groups, $t(71)=0.06, p=n s$. Although pubertal status was not determined in order to increase the acceptability of the study to the parents, children, and camp administrators, the average age of puberty in the USA is 12.5 years [31] and the proportion of girls above and below the age of 12.5 did not differ according to $A B$ status, $x^{2}(1)=0.13, p=n s$.

Further, there were no significant differences in measures of body size or physical fitness between the Ad-36 AB+ and Ad-36 AB- groups (table 2). With regard to lipids, the Ad-36 AB+ youth evidenced significantly lower levels of total cholesterol and triglycerides than the Ad-36 AB- youth ( $<<0.05)$, but not of LDL ( $<<0.10$ ) or HDL. As BMI is associated with lipids and physical fitness, differences in indices of physical fitness and lipids were also tested while controlling for z-BMI. Ad-36+ youth had higher systolic, but not diastolic blood pressures ( $\mathrm{p}$ $<0.05$ ). No differences in other measures of fitness were obtained. Differences in lipids were maintained.

\section{Manipulation Check}

The effectiveness of the intervention was tested as a manipulation check. The entire group showed significant improvements in measures of body size and fitness. Improvements in the Ad-36 AB+ and Ad-36 AB- groups were then tested individually. Results showed statistically significant improvements in every area of body size and fitness for each group. Tables of these results are available from the first author. 
Table 2. Baseline differences between Ad-36 AB+ and AB- youth

\begin{tabular}{|c|c|c|c|c|c|c|c|}
\hline & \multicolumn{3}{|c|}{ Ad-36 AB+ } & \multicolumn{3}{|c|}{ Ad-36 AB- } & \multirow[t]{2}{*}{$\mathrm{F}$} \\
\hline & $\mathrm{n}$ & mean & SD & $\mathrm{n}$ & mean & SD & \\
\hline \multicolumn{8}{|l|}{ Body size } \\
\hline Height, cm & 16 & 157.40 & 7.80 & 55 & 159.91 & 9.72 & 0.90 \\
\hline Weight, kg & 16 & 84.70 & 15.13 & 55 & 87.71 & 21.83 & 0.27 \\
\hline BMI, $\mathrm{kg} / \mathrm{m}^{2}$ & 16 & 34.14 & 5.29 & 55 & 33.89 & 6.04 & 0.02 \\
\hline BMI percentile & 16 & 97.82 & 3.20 & 55 & 98.25 & 1.57 & 0.61 \\
\hline z-BMI & 16 & 2.21 & 0.41 & 55 & 2.23 & 0.34 & 0.02 \\
\hline Neck circumference, $\mathrm{cm}$ & 16 & 35.82 & 2.69 & 55 & 36.95 & 3.54 & 0.61 \\
\hline Waist circumference, $\mathrm{cm}$ & 16 & 110.54 & 15.76 & 55 & 114.11 & 16.19 & 0.23 \\
\hline Hip circumference, cm & 16 & 113.72 & 10.43 & 55 & 111.55 & 13.65 & 0.03 \\
\hline \multicolumn{8}{|l|}{ Lipids } \\
\hline Cholesterol, mg/dl & 16 & 156.31 & 25.83 & 54 & 177.30 & 39.40 & $4.00^{*}$ \\
\hline $\mathrm{HDL}, \mathrm{mg} / \mathrm{dl}$ & 16 & 39.18 & 9.70 & 54 & 37.84 & 9.76 & 0.23 \\
\hline $\mathrm{LDL}, \mathrm{mg} / \mathrm{dl}$ & 16 & 99.87 & 22.13 & 54 & 116.27 & 33.07 & $3.45^{\mathrm{t}}$ \\
\hline $\mathrm{TG}, \mathrm{mg} / \mathrm{dl}$ & 16 & 86.31 & 43.36 & 54 & 116.36 & 55.48 & $3.95^{*}$ \\
\hline \multicolumn{8}{|l|}{ Fitness } \\
\hline BP systolic, mm Hg & 16 & 130.88 & 19.16 & 55 & 121.71 & 16.34 & $3.60^{\mathrm{t}}$ \\
\hline BP diastolic, mm Hg & 16 & 72.25 & 9.74 & 55 & 72.33 & 9.43 & 0.00 \\
\hline Run time, min & 16 & 15.09 & 3.15 & 55 & 15.42 & 3.13 & 0.13 \\
\hline Sit-ups/min, $\mathrm{n}$ & 16 & 40.25 & 13.30 & 55 & 40.11 & 11.19 & 0.00 \\
\hline
\end{tabular}

$\mathrm{BP}=$ Blood pressure; $\mathrm{TG}=$ triglycerides. ${ }^{\mathrm{t}} \mathrm{p}<0.07 .{ }^{*} \mathrm{p}<0.05$.

\section{Outcomes}

Differences in 4-week outcomes of body size and fitness between Ad-36 AB+ and Ad-36 $\mathrm{AB}$ - groups were assessed treating baseline values as covariates (table 3). The Ad-36 AB+ group showed a smaller reduction in BMI percentile $(p<0.05)$ and in $z-B M I(p<0.09)$ than the Ad-36 AB- group. However, the Ad-36 AB+ group evidenced a non-significantly greater reduction in diastolic blood pressure $(p<0.07)$ than the Ad-36 AB-group. There were no other significant differences with regard to indices of body size or fitness. When the changes in fitness were re-examined while controlling for changes in z-BMI, the Ad-36 AB+ group evidenced a greater reduction in diastolic blood pressure $(p<0.03)$ than the Ad-36 AB- group.

\section{Predictors of Outcomes}

Predictors of changes in z-BMI were examined, including baseline demographic characteristics, lipids, and measures of body size and fitness. Significant predictors included age, $\mathrm{F}(1,69)=10.84, \mathrm{p}<0.002, \mathrm{R}^{2}{ }_{\text {Adj }}=0.12 ; \mathrm{z}-\mathrm{BMI}, \mathrm{F}(1,69)=86.34, \mathrm{p}<0.0001, \mathrm{R}^{2}$ Adj $=0.39$; waist circumference, $\mathrm{F}(1,47)=59.23, \mathrm{p}<0.0001 . \mathrm{R}^{2}$ Adj $=0.55$; and diastolic blood pressure and 1 mile run time, $\mathrm{F}(2,68)=11.80, \mathrm{p}<0.0001, \mathrm{R}^{2}$ Adj $=0.24$.

\section{Discussion}

This is the first study to examine whether Ad-36 AB status is associated with response to a comprehensive weight loss treatment program among youth in the USA, including measures of body size and fitness. Further, this is the first study to determine whether Ad-36 AB status was associated with lipids among youth in the USA. 
Vander Wal et al.: An Observational Study of the Association between Adenovirus 36 Antibody Status and Weight Loss among Youth

Table 3. Differences between Ad-36 AB+ and AB- youth in 4-week outcomes, controlling for baseline values

\begin{tabular}{|c|c|c|c|c|c|c|c|}
\hline & \multicolumn{3}{|c|}{ Ad-36 AB+ } & \multicolumn{3}{|c|}{ Ad-36 AB- } & \multirow[t]{2}{*}{$\mathrm{F}$} \\
\hline & $\mathrm{n}$ & mean & SD & $\mathrm{n}$ & mean & SD & \\
\hline \multicolumn{8}{|l|}{ Body size variables } \\
\hline Height, cm & 16 & 0.28 & 0.40 & 55 & 0.39 & 0.53 & 0.61 \\
\hline Weight, kg & 16 & -6.43 & 1.74 & 55 & -6.91 & 2.41 & 0.29 \\
\hline BMI, $\mathrm{kg} / \mathrm{m}^{2}$ & 16 & -2.71 & 0.73 & 55 & -2.81 & 0.76 & 0.53 \\
\hline BMI percentile & 16 & -1.24 & 1.65 & 55 & -1.39 & 5.02 & $5.02^{*}$ \\
\hline z-BMI & 16 & -0.19 & 0.06 & 55 & -0.22 & 0.75 & $2.98^{\mathrm{t}}$ \\
\hline Neck circumference, $\mathrm{cm}$ & 12 & -1.38 & 0.89 & 37 & -1.75 & 1.03 & 0.49 \\
\hline Waist circumference, $\mathrm{cm}$ & 12 & -6.56 & 8.04 & 37 & -7.17 & 2.91 & 0.16 \\
\hline Hip circumference, cm & 12 & -5.98 & 2.38 & 37 & -6.21 & 2.77 & 0.45 \\
\hline \multicolumn{8}{|l|}{ Fitness variables } \\
\hline BP systolic, mm Hg & 12 & -14.33 & 13.88 & 37 & -6.92 & 10.36 & 0.07 \\
\hline BP diastolic, mm Hg & 12 & -6.83 & 7.36 & 37 & -4.32 & 5.26 & $3.64^{\mathrm{t}}$ \\
\hline Run time, min & 12 & -3.81 & 1.33 & 37 & -4.14 & 1.84 & 0.85 \\
\hline Strength & 12 & 15.08 & 13.62 & 37 & 14.21 & 9.31 & 0.12 \\
\hline
\end{tabular}

BP $=$ Blood pressure. ${ }^{t} \mathrm{p}<0.10 ;{ }^{*} \mathrm{p}<0.05$.

Results of the present study showed that the Ad-36 AB+ group had a better lipid profile than the Ad-36 AB- group. These results are consistent with a one study conducted among children [26], but inconsistent with a second child study [27] which showed that obese Ad-36 $\mathrm{AB}+$ children had higher cholesterol and triglyceride values than obese Ad-36 AB-children. Unlike the two previous studies that examined associations between Ad-36 AB status and lipid profiles among children, the $\mathrm{AB}+$ youth in the present study did not have greater waist circumferences than the Ad-36 AB- youth. Among adults, greater waist circumference is a marker of the metabolic syndrome, or a pattern of abnormalities associated with obesity including hypertension, elevated lipids, and impaired glucose tolerance. However, evidence for the role of waist circumference in the metabolic syndrome among youth is less clear [32]. Evidence also suggests that the metabolic syndrome may develop at earlier stages of obesity among persons of Asian descent [33]. However, the present study sample was predominantly White.

The Ad-36 AB+ group showed only a slightly lower response to weight loss than the Ad-36 AB- group, with the only statistically significant difference being a smaller reduction in BMI percentile. The present study was only 4 weeks in duration; a longer period of time may be necessary to observe the degree to which, if any, these differential weight loss trajectories translate into biologically meaningful differences. The present sample was also obese. The finding that obese youth respond well to camp-based interventions [29] may have obscured the ability to detect differences in treatment response according to Ad-36 AB status that could occur among youth with less weight to lose. Finally, given the logistical constraints of serving meals to youth in a camp setting, a standardized diet, stratified by gender, but not body size, was used. This approach may have produced greater weight loss among larger youth.

Successful weight loss among adolescents is historically very difficult to achieve [34, 35]. Importantly, this short-term intervention itself proved to be highly efficacious, producing an average weight loss of $6.80 \mathrm{~kg}$, a $7.02 \mathrm{~cm}$ reduction in waist circumference, and a decrease of 4.02 min in 1-mile run times in just 4 weeks. These results are consistent with a previous 
Vander Wal et al.: An Observational Study of the Association between Adenovirus 36

evaluation of this same camp [29]. Residential weight loss camps afford the advantages of tight control over diet and physical activity, supportive peer and staff relationships, and establishment of an environment conducive to successful weight management. Importantly, the camp provides year-round youth and family support via regularly scheduled conference calls and maintenance of an interactive website. However, the degree to which the weight loss was maintained is unknown. Future studies are needed to examine the long-term efficacy of such interventions.

Baseline predictors of change in z-BMI included age and initial z-BMI, waist circumference, diastolic blood pressure, and 1-mile run time. Neither Ad-36 AB status nor lipids entered the regression equations. These results are consistent with the finding that the Ad-36 $\mathrm{AB}+$ and $\mathrm{Ad}-36 \mathrm{AB}-$ youth were of comparable baseline $\mathrm{z}-\mathrm{BMI}$ and lost comparable amounts of weight. Presumably, the use of a standardized intervention involving the same level of dietary intake and physical activity regardless of age resulted in a larger net caloric deficit among older and larger youth.

In addition to the aforementioned limitations, the sample was predominantly White, female, and obese, limiting generalizability to other racial and ethnic groups, male youth, and overweight populations. Further, the time span of the present study, only 4 weeks in duration, was very brief. Finally, to increase acceptability of the study to the parents, youth, and camp administrators, pubertal staging was not conducted; however, future studies may benefit from including Tanner staging as a covariate.

Considerable attention is focused on determining reference values for cardiovascular risk factors for children, including indices of adiposity, lipid levels, and blood pressure [36], and on modulating these risk factors by intervention [37]. Such studies often control for the potential contribution of confounding factors such as age, sex, adiposity, and pubertal status to cardiovascular risk factors, but not of Ad-36 infection, waist circumference, or ethnicity, which could also influence results. Inclusion of these measures may be necessary to better appreciate their role, if any, in obesity prevention and treatment strategies. Larger and longer term studies are needed to examine the association between Ad-36 AB status and weight loss and maintenance as well as changes in lipid values over time.

\section{Acknowledgement}

This study was funded by the Beaumont Faculty Development Fund, awarded by Saint Louis University, St. Louis, MO, USA.

\section{Disclosure Statement}

Dr. Vander Wal is a volunteer member of the Board of Advisors for the non-profit Living Well Foundation which houses Camp Jump Start, the residential weight loss camp referenced in the manuscript.

Ms. Huelsing is the founder of Camp Jump Start and the CEO of the Living Well Foundation, which houses Camp Jump Start.

Dr. Dhurandhar holds the following United States Patents: Patent number 6,127,113: Viral obesity methods and compositions. Patent number 6,664,050: Viral obesity methods and compositions. Patent number US 8,008,436B2, dated August 30, 2011: Adenovirus 36 E4orf1 gene and protein and their uses. Provisional patent filed: Adenovirus Ad36 E4orf1 protein for prevention and treatment of non-alcoholic fatty liver disease, July 2010. Provisional patent filed: Enhanced glycemic control using Ad36E4orf1 and AKT1 Inhibitor. January 2012. 
Vander Wal et al:: An Observational Study of the Association between Adenovirus 36 Antibody Status and Weight Loss among Youth

\section{References}

1 Ogden CL, Carroll, MD, Curtin LR, McDowell MA, Tabak CJ, Flegal KM: Prevalence of overweight and obesity in the United States, 1999-2004. JAMA 2006;295:1549-1555.

-2 Freedman DS, Dietz WH, Srinivasan SR, Berenson GS: The relation of overweight to cardiovascular risk factors among children and adolescents. The Bogalusa Heart Study. Pediatrics 1999;1031175-1182.

-3 Weiss R, Dziura J, Burgert, Tamborlane WV, Taksali SE, Yeckel CW, Allen K, Lopes M, Savoye M, Morrison J, Sherwin RS, Caprio S: Obesity and the metabolic syndrome in children and adolescents. N Engl J Med 2004; 350:2362-2374.

4 Engeland A, Bjorge T, Sogaard AJ, Tverdal A: Body mass index in adolescence in relation to total mortality: 32-year follow-up of 227,000 Norwegian boys and girls. Am J Epidemiol 2003;157:517-523.

-5 Fontaine KR, Redden DT, Wang C, Westfall AO, Allison DB: Years of life lost due to obesity. JAMA 2003;289: 187-193.

-6 Vander Wal JS, Mitchell ER: Psychological complications of pediatric obesity. Pediatr Clin North Am 2011;58: 1393-1401.

7 Keith SW, Redden DT, Katzmarzyk PT, Boggiano MM, Hanlon EC, Benca RM, Ruden D, Pietrobelli A, Barger JL, Fontaine KR, Wang C, Aronne LJ, Wright SM, Baskin M, Dhurandhar NV, Lijoi MC, Grilo CM, DeLuca M, Westfall AO, Allison DB: Putative contributors to the secular increase in obesity: exploring the roads less traveled. Int J Obes 2006;30:1585-1594.

8 Brownell KD: Public policy and the prevention of obesity; in Fairburn CG (ed): Eating Disorders and Obesity: A Comprehensive Handbook. New York, Guilford, 2001, pp 619-624.

-9 McAllister EJ, Dhurandhar NV, Keith SW, Aronne LJ, Barger J, Baskin M, Benca RM, Biggio J, Boggiano MM, Eisenmann JC, Elobeid M, Fontaine KR, Gluckman P, Hanlon EC, Katzmarzyk P, Pietrobelli A, Redden DT, Ruden DM, Wang C, Waterland RA, Wright SM, Allison DB: 10 putative contributors to the obesity epidemic. Crit Rev Food Sci Nutr 2009;49:868-913.

10 Dhurandhar NV, Israel BA, Kolesar JM, Mayhew GF, Cook ME, Atkinson RL: Increased adiposity in animals due to a human virus. Int J Obes Relat Metab Disord 2000;24:989-996.

11 Dhurandhar NV, Israel BA, Kolesar JM, Mayhew GF, Cook ME, Atkinson RL: Transmissibility of adenovirusinduced adiposity in a chicken model. Int J Obes Relat Metab Disord 2001;25:990-996.

-12 Dhurandhar NV, Whigham LD, Abbott DH, Schultz-Darken NJ, Israel BA, Bradley SM, Kemnitz JW, Allison DB, Atkinson RL: Human adenovirus Ad 36 promoted weight gain in male rhesus and marmoset monkeys. J Nutr 2002;132:3155-3160.

13 Na HN, Nam JH: Adenovirus 36 as an obesity agent maintains the obesity state by increasing MCP-1 and inducing inflammation. J Infect Dis 2012;205:914-922.

14 Pasarica M, Shin AC, Yu M, Yang HO, Rathod M, Jen KL, MohanKumar S, MohanKumar PS, Markward N, Dhurandhar NV: Human adenovirus 36 induced adiposity, increases insulin sensitivity, and alters hypothalamic monoamines in rats. Obesity (Silver Spring) 2006;14:1905-1913.

15 Dhurandhar NV: A framework for identifying infections that contribute to human obesity. Lancet Infect Dis 2011;11:963-969.

-16 Atkinson RL, Dhurandhar NV, Allison DB, Bowen RL, Israel BA, Albu JB, Augustus AS: Human adenovirus-36 is associated with increased body weight and paradoxical reduction of serum lipids. Int J Obes 2005;29:281286.

17 Trovato GM, Castro A, Tonzuso A, Garozzo A, Martines GF, Pirri C, Trovato F, Catalano Dl: Human obesity relationship with Ad36 adenovirus and insulin resistance. Int J Obes 2009;33:1402-1409.

18 Trovato GM, Martines GF, Garozzo A, Tonzuso A, Timpanaro R, Pirri C, Trovato FM, Catalano D: Ad36 adipogenic adenovirus in human non-alcoholic fatty liver disease. Liver Int 2010;30:184-190.

19 Trovato GM, Martines, GF, Trovato FM, Pirri C, Pace P, Garozzo A, Castro A, Catalano D: Adenovirus-36 seropositivity enhances effects of nutritional intervention on obesity, bright liver, and insulin resistance. Dig Dis Sci 2012;57:535-544.

20 Broderick MP, Hansen CJ, Irvine M, Metzgar D, Campbell K, Baker C, Russell KL: Adenovirus 36 seropositivity is strongly associated with race and gender, but not obesity, among US military personnel. Int J Obes 2010;34: 302-308.

-21 Goossens VJ, Dejager SA, Grauls GE, Gielen M, Vlietinck RF, Derom CA, Loos RJF, Rensen SS, Buurman WA, Greve JW, van Baak MA, Wolffs PF, Bruggeman CA, Hoebe CJPA: Lack of evidence for the role of human adenovirus-36 in obesity in a European cohort. Obesity (Silver Spring) 2011;19:220-221.

22 Atkinson RL: Prevalence of infection with adenovirus-36 in Belgium and Holland and association with obesity. Obesity (Silver Spring) 2011;19:2.

-23 Goossens VJ, Wolffs PF, Bruggeman CA: Response to 'Prevalence of infection with adenovirus in Belgium and Holland and association with obesity.' Obesity (Silver Spring) 2011;19:3.

24 Na HN, Kim J, Lee HS, Shim KW, Kimm H, Jee SH, Jo I, Nam J-H: Association of human adenovirus-36 in overweight Korean adults. Int J Obes 2012;36:281-285.

25 Gabbert C, Donohue M, Arnold J, Schwimmer JB: Adenovirus 36 and obesity in children and adolescents. Pediatrics 2010;126:721-726.

26 Atkinson RL, Lee I, Shin HJ, He J: Human adenovirus-36 antibody status is associated with obesity in children. Int J Pediatr Obes 2010;5:157-160. 
Vander Wal et al.: An Observational Study of the Association between Adenovirus 36 Antibody Status and Weight Loss among Youth

-27 Na HN, Hong YM, Kim J, Kim HK, Jo I, Nam JH: Association between human adenovirus-36 and lipid disorders in Korean schoolchildren. Int J Obes 2010;34:89-93.

28 Centers for Disease Control and Prevention: Epi Info (Version 3.3.2)(computer software), 2005. Retrieved from www.cdc.gov/epiinfo/.

29 Huelsing J, Kanafani N, Mao J, White NH: Camp Jump Start: effects of a residential summer weight-loss camp for older children and adolescents. Pediatrics 2010;125:884-890.

30 Dimitrov DM, Rumrill PD Jr: Pretest-posttest designs and measurement of change. Work 2003;20:159-165.

31 Anderson SE, Dallal GE, Must A: Relative weight and race influence average age at menarche: results from two nationally representative surveys of US girls studied 25 years apart. Pediatrics 2003;111:844-850.

-32 Barlow SE: Expert committee recommendations regarding the prevention, assessment, and treatment of child and adolescent overweight and obesity: summary report. Pediatrics 2007;120(suppl 4):S164-192.

-33 World Health Organization: Appropriate body-mass index for Asian populations and its implications for policy and intervention strategies. Lancet 2004;363:157-163.

-34 Reinehr T, Kleber M, Lass N, Toschke AM: Body mass index patterns over $5 \mathrm{y}$ in obese children motivated to participate in a 1-y lifestyle intervention: age as a predictor of long-term success. Am J Clin Nutr 2010;91: 1165-1171.

35 Reinehr T, Widhalm K, L'Allemand D, Wiegand S, Wabitsch M, Holl RW: Two-year follow-up in 21,784 overweight children and adolescents with lifestyle intervention. Obesity 2009;17:1196-1199.

-36 Mellerio H, Alberti C, Druet C, Capelier F, Mercat I, Josserand E, Vol S, Tichet J, Levy-Marchal C: Novel modeling of reference values of cardiovascular risk factors in children aged 7 to 20 years. Pediatrics 2012;129:e10201029.

-37 Ekelund U, Luan J, Sherar LB, Esliger DW, Griew P, Cooper A; International Children's Accelerometry Database (ICAD) Collaborators: Moderate to vigorous physical activity and sedentary time and cardiometabolic risk factors in children and adolescents. JAMA 2012 307:704-712. 